Brazilian Journal

of Chemical

ISSN 0104-6632

Engineering

Printed in Brazil

www.scielo.br/bjce

Vol. 34, No. 03, pp. 681 - 690, July - September, 2017

$($ (c) $)$ EY

dx.doi.org/10.1590/0104-6632.20170343s20150575

\title{
PRODUCTION OF FLAVOR ESTERS CATALYZED BY LIPASE B FROM Candida antarctica IMMOBILIZED ON MAGNETIC NANOPARTICLES
}

\author{
M. C. M. de Souza ${ }^{1,2}$, K. P. dos Santos ${ }^{2}$, R. M. Freire ${ }^{3}$, A. C. H. Barreto ${ }^{3}$, \\ P. B. A. Fechine ${ }^{3}$ and L. R. B. Gonçalves ${ }^{2 *}$ \\ ${ }^{1}$ Grupo Interdisciplinar em Química, Instituto de Engenharias e Desenvolvimento Sustentável. Universidade da Integração Internacional da \\ Lusofonia Afro-Brasileira, UNILAB, Campus dos Palmares Rodovia CE 060 Km 51, Acarape-CE, CEP 62785-000 \\ ${ }^{2}$ Grupo de Pesquisa e Desenvolvimento de Processos Biotecnológicos (GPBIO), Departamento de Engenharia Química, \\ Universidade Federal do Ceará, UFC, Campus do Pici, Bloco 709, Fortaleza-CE, CEP 60455-760 \\ *E-mail: 1rg@ufc.br; Phone: +55 85 33669611; Fax: +55 8533669610
}

${ }^{3}$ Grupo de Química de Materiais Avançados (GQMAT), Departamento de Química Analítica e Físico-Química, Universidade Federal do Ceará, UFC, Campus do Pici,CEP 12100, Fortaleza-CE, CEP 60451-970, Brazil, Brazil

(Submitted: September 10, 2015; Revised: January 29, 2016; Accepted: March 21, 2016)

\begin{abstract}
Candida antarctica Lipase B (CALB) immobilized onto iron magnetic nanoparticles was evaluated as biocatalyst for the synthesis of flavor esters. Methyl and ethyl butyrate were synthesized by esterification of butyric acid with methanol and ethanol, respectively, in a medium containing solvent. The nanoparticles were produced by the co-precipitation method. The process parameters (type of solvent, temperature, substrate concentration, molar ratio, amount of biocatalyst, stirring speed and reaction time) were studied. The optimum conditions for both esters were achieved at $25^{\circ} \mathrm{C}, 0.5 \mathrm{~mol} / \mathrm{L}$ (methyl butyrate) and $0.4 \mathrm{~mol} / \mathrm{L}$ (ethyl butyrate), molar ratio of 1:1, amount of biocatalyst: $10 \mathrm{mg}, 150 \mathrm{rpm}$ and $8 \mathrm{~h}$ of reaction, using heptane as solvent. Under those conditions, the maximum conversions of methyl butyrate and ethyl butyrate were higher than $90 \%$. The synthesis of flavor esters was also conducted by using Novozym ${ }^{\circledR} 435$, a commercial catalyst, for comparison purposes.
\end{abstract}

Keywords:Candida antarctica Lipase B, Magnetic nanoparticles, Flavor esters

\section{INTRODUCTION}

Short-chain fatty acid esters are an important group of flavor and fragrance compounds widely used in food, beverage, cosmetic and pharmaceutical industries (Xu et al., 2002; Jin et al., 2012). These aromas are typically extracted from natural sources; however, some problems arise due to environmental questions (Bjorkling et al., 1991; Xu et al., 2002). Whereas the current synthesis of these compounds uses liquid acids as catalysts and requires post-treatment (Ben Salah et al., 2007), an alternative route applying enzymes may also be employed, obtaining products that are considered to be natural (Gillies et al., 1987). In this context, lipases (glycerol ester hydrolases, EC 3.1.1.3) are a diverse group of enzymes that are able to act in the organic-aqueous interface, being a good option for esterification and other synthetic reactions (Uppenberg et al. 1994; Idris et al.,2011) occurring in organic media. Lipases produced by Candida sp. are well-established enzymes for biocatalysis purposes, especially Candida antarctica lipase B (CALB) (Dominguez de Maria et al., 2005). CALB has been studied for potential applications

\footnotetext{
* To whom correspondence should be addressed
} 
in many different sectors, such as food and flavor making, detergent, pharmaceutical, textile, cosmetic, paper and oleochemical industries (Hasan et al., 2006; Hung et al., 2003). These applications are possible due to the wide range of specificity for substrates, high activity for several different reactions under mild conditions, resistance to organic solvents, high thermal and $\mathrm{pH}$ stability, and stereospecificity (Rodrigues et al., 2008, McCabe et al., 2005; Deng et al., 2011).

The use of immobilized lipase is recommended in order to overcome some enzyme limitations, such as: solubility, purity, activity, inhibition and poor stability. Furthermore, immobilization presents other advantages that include reusability, easier control of the reaction, use of different reactor configurations, etc.(Gárcia-Galan et al., 2011; Silva et al., 2012; Gomes et al.,2004). In the last years, nanoparticles have been shown to be an immobilization support of great importance due to a substantial increase in their availability and versatility. The use of magnetic particles has been considered as a novel strategy for Smart Immobilization of enzymes via covalent attachment (Vaghari et al., 2015). Moreover, the use of this support in industrial reactors has been greatly encouraged since the appearance of paramagnetic nanoparticles, as recovery and reuse of thismaterial can be accomplished by simply exposing the system to a magnetic field (Gárcia-Galan et al., 2011). Besides, nanoparticles offer a high surface/ volume ratio (Ansari et al., 2012) which can be properly modified to attach enzymes (Tartaj et al., 2003), resulting in a high biocatalyst concentration in the support. For instance, hydroxyl groups can be used to define attachment points for functionalizing agents (Barreto et al., 2012, Boyer et al., 2010) and enzyme immobilization. Another important feature of these non-porous supports is the smaller size of the particles, resulting in a reduction of the diffusion hindrance (Zheng et al., 2003).As a result, a significant progress in the last few years has been made in the use of magnetic nanoparticles as carrier for the binding of enzymes. Nevertheless, the immobilized enzymes still present some drawbacks, such as change in properties and low efficacy against insoluble substrates (Vaghari et al., 2015). For this reason, further research is yet needed in order to address these limitations and allow industrial application.

With this in mind, in the present work, methyl and ethyl butyrate (i.e., substances that are highly demanded in food industries as components of pineapple/banana flavors) were successfully produced employing CALB immobilized onto magnetic nanoparticles (CALB-MNP) (Gillies et al., 1987). The influences of the temperature, substrate concentration, acid:alcohol molar ratio, amount of biocatalyst, stirring speed, reaction time and type of solvent on methyl and ethyl butyrate synthesis were investigated. The results were then compared to those obtained by using a commercial biocatalyst (CALB immobilized in acrylic resin - Novozym ${ }^{\circledR} 435$ ). Last but not least, the operational stability of the biocatalysts was also investigated.

\section{METHODS}

\section{Materials}

Lipase B from Candida antartica (CALB) was purchased from Codexis (Redwood, USA). Lipase B from Candida antartica immobilized in acrylic resin (Novozym ${ }^{\circledR} 435$ ), $\gamma$-aminopropyltriethoxysilane (APTS), glutaraldehyde solution Grade II $25 \%$ (w/v), p-nitrophenyl butyrate (pNPB) and p-nitrophenol (pNP) were purchased from Sigma-Aldrich (St. Louis, USA). Iron magnetic nanoparticles () were produced by the co-precipitation method. The chemical reagents used for this synthesis were $\mathrm{FeCl}_{3} \cdot 6 \mathrm{H}_{2} \mathrm{O}$ (pure granulated $99 \%$ ), $\mathrm{FeSO}_{4} \cdot 7 \mathrm{H}_{2} \mathrm{O}$ (pure granulated 99\%) and 30\% ammonia solution. All other reagents (analytical grade) were purchased from Synth (São Paulo, Brazil) and Vetec (São Paulo, Brazil).

\section{Production of magnetic nanoparticles}

Iron magnetic nanoparticles (), here named MNP, were obtained by the co-precipitation method to obtain a particlesize of $11.0 \mathrm{~nm}$ (Barreto et al., 2012).

\section{APTS-modified nanoparticles}

nanoparticles were modified with the addition of an APTS $(2.0 \% \mathrm{v} / \mathrm{v})$ solution to the support in a liquidsolid ratio of $0.2(\mathrm{~mL} / \mathrm{mg}$ of support). The solution was heated at $100{ }^{\circ} \mathrm{C}$ for 10 hours under nitrogen atmosphere. The nanoparticles were then washed with methanol and ethanol, and separated by magnetic decantation. After that, the material was dried at $30{ }^{\circ} \mathrm{C}$ for 24 hours (Netto et al., 2009).

\section{Glutaraldehyde crosslinking}

Nanoparticles modified by APTS $(0.01 \mathrm{~g})$ were suspended in a $25 \%(\mathrm{w} / \mathrm{v})$ glutaraldehyde solution with 2.5 ratio solution/support (mL.). The reaction was allowed to proceed at $25^{\circ} \mathrm{C}, 45 \mathrm{rpm}$ for $2 \mathrm{~h}$. After that, the resultant APTS-modified and crosslinked nanoparticles (MNP) were separated by magnetic decantation and washed with a $100 \mathrm{mM}$ bicarbonate buffer, $\mathrm{pH} 10$, to remove the excess of crosslinker agent. The glutaraldehyde crosslinking was performed in triplicate and the results expressed as means and standard deviations.

\section{CALB Immobilization}

The modified and crosslinked nanoparticles $(0.01 \mathrm{~g})$ were added to $0.5 \mathrm{~mL}$ of $100 \mathrm{mM}$ sodium bicarbonate 
buffer solution, $\mathrm{pH}=10$, at $25^{\circ} \mathrm{C}$, containing $19 \mu \mathrm{L}$ of CALB solution (enzyme load of $80 \mathrm{U}$. support, theoretical activity,). The system was stirred (45 rpm) for $1 \mathrm{~h}$. The immobilized CALB, named CALB-MNP, was removed by magnetic separation and washed with a sodium phosphate buffer (25 mM, pH 7). The immobilization of lipase was performed in triplicate and the results expressed as means and standard deviations. The amount of CALB immobilized on MNP was determined by measuring the initial and final protein concentration in the immobilization supernatant by the Bradford method (Bradford, 1976). Hydrolytic activities were also determined in order to calculate the immobilization parameters (Silva et al., 2012), such as: immobilization yield $(I Y)$, theoretical activity $\left(A t_{t}\right)$ and recovery activity $\left(A t_{r}\right)$.

\section{Assay of Hydrolytic Activity}

The hydrolytic activity of CALB was determined using p-nitrophenyl butyrate (pNPB) as substrate, in 2-propanol, at $\mathrm{pH} 8.0$ and $25^{\circ} \mathrm{C}$, according to the methodology described in the literature (Silva et al., 2012). One unit of lipase activity was defined as the amount of enzyme that hydrolyses pNPB liberating $1 \mu \mathrm{mol}$ of the $\mathrm{p}$-nitrophenoxide ion per minute under assay conditions.

\section{Enzymatic esterification}

The production of esters by esterification was conducted in a reaction medium containing $1 \mathrm{~mL}$ of solvent (heptane, hexane, cyclohexane or 1,4-dioxane), butyric acid and alcohol (methanol or ethanol) in different concentrations (0.2-1.0 moL/L) and molar ratios (1:1-1:4). A biocatalyst mass (CALB-MNP) of $0.01 \mathrm{~g}$ was added (enzyme load: 80 U.) to initiate the reaction, which was carried out under orbital stirring $(50-250 \mathrm{rpm})$, at $25-55^{\circ} \mathrm{C}$. The reactions were performed in triplicate and the results expressed as means and standard deviations.Conversion was monitored by determining the acid index through the Ca 5-40 AOCS method (AOCS, 2013). For comparison, the esterification was also conducted by using Novozym ${ }^{\circledR} 435$ at the reaction conditions where maximum conversion was achieved with CALB-MNP.

\section{Operational Stability}

The operational stability of the immobilized enzyme was evaluated by submitting $0.01 \mathrm{~g}$ of CALB-MNP to subsequent cycles of methyl and ethyl butyrate synthesis. Before each new cycle, the immobilized enzyme was separated by magnetization and washed with $0.5 \mathrm{~mL}$ of hexane solvent (3 times) for product and unreacted substrate removal. The reactions were performed as described above.

\section{X-ray diffraction (XRD)}

The XRD analysis was carried out in a Rigaku X-ray powder diffractometer equipped with a tube $\operatorname{CuK} \alpha(\lambda=$ $1.54056 \AA$ ) operating at $40 \mathrm{kV} / 25 \mathrm{~mA}$. Powder samples were placed in the sample holder and the diffraction patterns were collected over a range of $2 \theta=20-100^{\circ}$ with a $0.02^{\circ}$ step. The values of particle size, lattice parameters and phase concentrations were evaluated from the mathematical treatment of the diffraction patterns obtained by the Rietveld Method. The structural data derived from XRD was also determined using the DBWTools version 2.3 program (Bleicher et al., 2000).

\section{Infrared Spectroscopy (FTIR)}

Fourier transform infrared spectroscopy (FTIR) measurements were performed using a Perkin Elmer 2000 spectrophotometer in the 400 to $4000 \mathrm{~cm}^{-1}$ range. The samples were previously dried, ground to a powder and pressed $(10 \mu \mathrm{g}$ of sample to $100 \mathrm{mg}$ of $\mathrm{KBr})$ in disk format for measurements.

\section{RESULTS AND DISCUSSION}

\section{MNP and immobilized lipase characterization and immobilization study}

Figure 1 shows the XRD pattern of the sample after the NP mathematical treatment of data by the Reitveld method. An ICSD standard and a sample of MNP were used. The Crystallographic peaks and Miller indices of $21.4^{\circ}$ (111), $35.2^{\circ}(220), 41.6^{\circ}(311), 50.7^{\circ}$ (400) $63.2^{\circ}(422), 67.5^{\circ}$ (511) and $74.4^{\circ}(440)$ found in the sample are in agreement with the literature (Kim et al., 2012). These data are related to a cubic crystal system Fd-3m (227), resembling the unit cells for spinel magnetite. One can use the crystallite size to calculate the particle size, because in nanosystems with a single domain the crystallite sizeis presumablyclose to that of the particle. The particle size was estimated by the Scherrer method, obtaining a value of $14.87 \mathrm{~nm}$.

Figure 2 shows the recorded FTIR spectra of the samples $\left(\mathrm{Fe}_{3} \mathrm{O}_{4}, \mathrm{Fe}_{3} \mathrm{O}_{4}+\right.$ APTES, $\mathrm{Fe}_{3} \mathrm{O}_{4}+$ APTES + Glutaraldehyde + Lipase and Lipase) in the range of $4000-400 \mathrm{~cm}^{-1}$. The immobilized enzyme $\left(\mathrm{Fe}_{3} \mathrm{O}_{4}+\right.$ APTES + Glutaraldehyde + Lipase) presented an immobilization yield of 53\% and an activity per gram of support of $80 \mathrm{UpNPB}$. For $\mathrm{Fe}_{3} \mathrm{O}_{4}$ nanoparticles (Fig. 2 (a)), it can be observed a band in the range of $650-400 \mathrm{~cm}^{-1}$, typical of metal in the tetrahedral $\left(T_{d}\right)$ site of a spinel lattice, confirming the presence of nanoparticles (Freire et al., 2013). Fig. 2 (b) shows the spectrum of the functionalized $\mathrm{Fe}_{3} \mathrm{O}_{4}$ with APTES. The covalent anchoring can be confirmed by the bands at 3427 and $1630 \mathrm{~cm}^{-1}$, assigned to $\mathrm{N}-\mathrm{H}$ and $\mathrm{NH}_{2}$ stretching, 


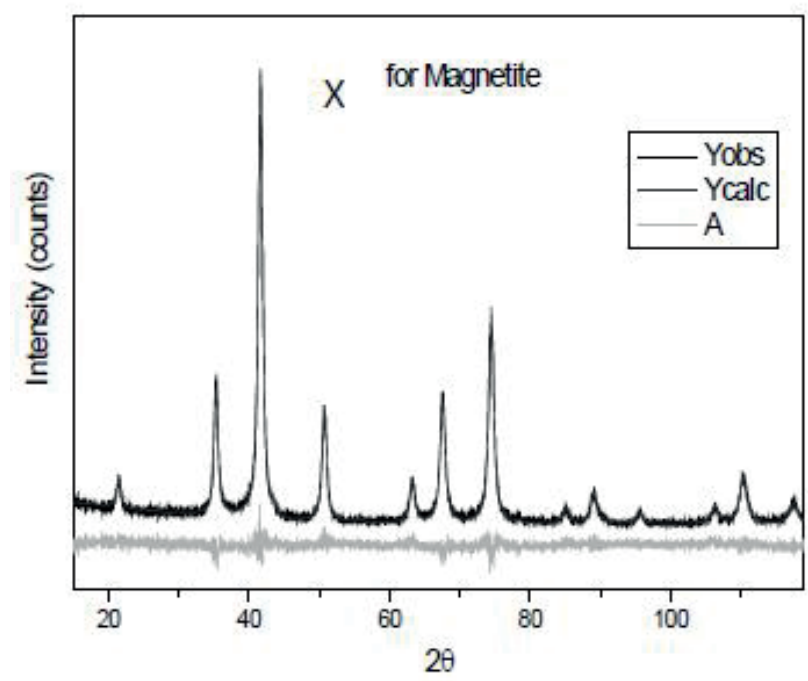

Figure 1. XRD pattern for the MNP sample after the mathematical treatment of data by the Reitveld refining method.

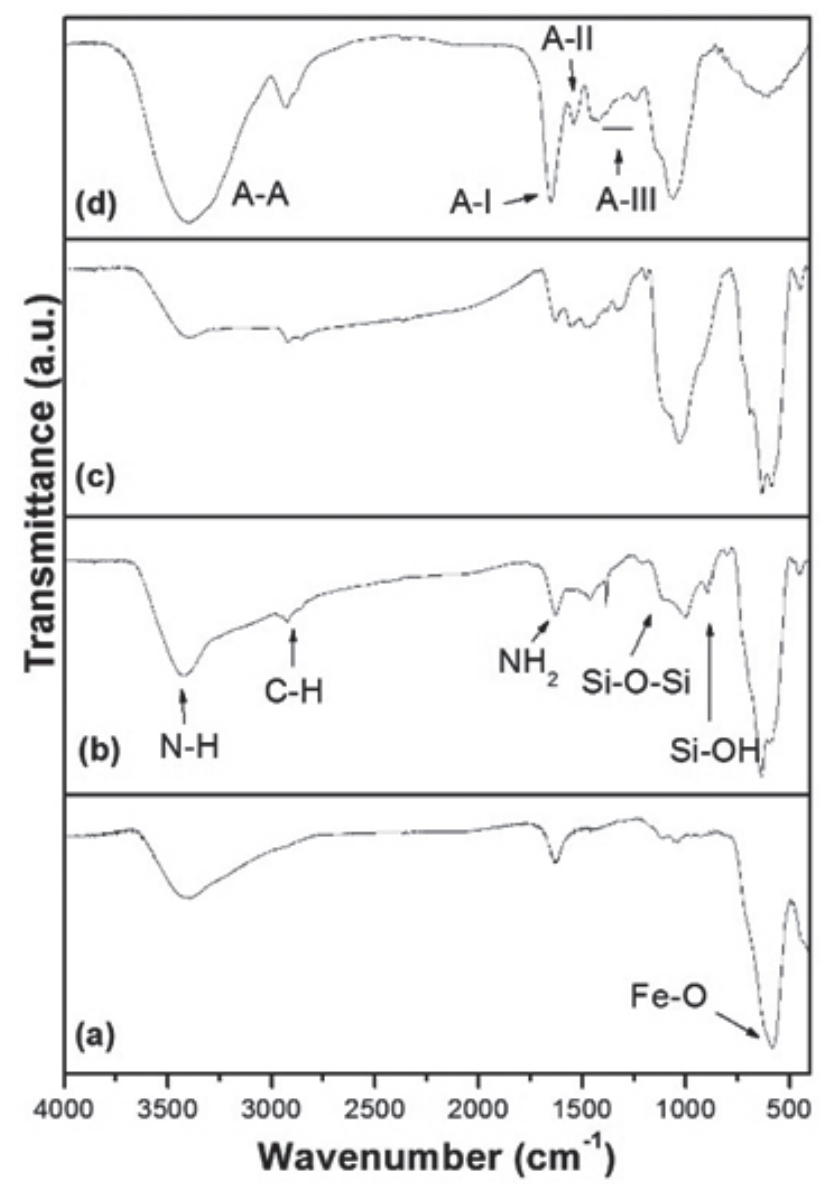

Figure 2. FTIR of the samples: (a) $\mathrm{Fe}_{3} \mathrm{O}_{4}$, (b) $\mathrm{Fe}_{3} \mathrm{O}_{4}+$ APTES, (c) $\mathrm{Fe}_{3} \mathrm{O}_{4}+$ APTES + Glutaraldehyde + Lipase and (d) Lipase.

respectively (Foresti et al., 2010). Bands related to Si-O groupswereobservedat $1116(\mathrm{Si}-\mathrm{O}-\mathrm{Si})$ and $894(\mathrm{Si}-\mathrm{OH}) \mathrm{cm}^{-1}$.

The presence of the propyl group was observed by bands at 2926 and $2853 \mathrm{~cm}^{-1}$, which are related to $\mathrm{C}-\mathrm{H}$ stretching. The resultant spectrum of the surface treatment with glutaraldehyde and lipase is shown in Fig. 2 (c) and no bands related $\left(1720 \mathrm{~cm}^{-1}\right.$ to free aldehyde groups $(-\mathrm{COH}))$ to glutaraldehyde were observed, suggesting that the enzyme was all bound to the functionalized $\mathrm{Fe}_{3} \mathrm{O}_{4}$ with APTES- glutaraldehyde, due to the reaction between the amine groups on the support and the available carbonyl groups of glutaraldehyde. Fig. 2 (d) shows a typical spectrum of free lipase for comparison. The bands found in Fig. 2 (d) can also be found in Fig. 2 (c), confirming the introduction of the lipases. A band in the range of $1700-1600 \mathrm{~cm}^{-1}$ was related to amide I (A-I) vibration, while a signal of lower intensity observed at $1541 \mathrm{~cm}^{-1}$ was assigned to symmetrical bending of the $\mathrm{N}-\mathrm{H}$ bonds, confirming amide II (A-II) vibration (Foresti et al., 2010). Bands observed around $1220-1330 \mathrm{~cm}^{-1}$ were attributed to Amide III (A-III) region. Furthermore, N-H bonds also showed a strong signal above $3000 \mathrm{~cm}^{-1}$ (A-A) region, characterizing amide $\mathrm{A}$. A broadening of the band between 3200 and $3400 \mathrm{~cm}^{-1}$ (Fig. 2c) is also observed, which is usually attributed to the stretch of $\mathrm{OH}$ and $\mathrm{NH}_{2}$, with exposure to glutaraldehyde.

\section{Effect of temperature}

The effect of temperature on the butyric acid conversion catalyzed by CALB-MNP (= 29.1 U. $\pm 0.01 \mathrm{~g})$ is shown in Figure 3.For methyl butyrate, the conversion remains constant from 15 up to $40^{\circ} \mathrm{C}$ and presents a sharp drop at 45 ${ }^{\circ} \mathrm{C}$. For ethyl butyrate, the conversion stays constant from 15 to $25^{\circ} \mathrm{C}$, shows a slow decrease until $45^{\circ} \mathrm{C}$ and then stabilizes. As methanol and ethanol have boiling points of $65{ }^{\circ} \mathrm{C}$ and $78.4{ }^{\circ} \mathrm{C}$, respectively, these distinct behaviors are probably due to their volatility differences. According to the literature (Cambon et al., 2009), conversion and methanol inhibition are very temperature dependent. This dependence was attributed to the thermodynamic state of the medium. The liquid-liquid equilibrium phase diagram and the liquid-vapor partitioning coefficient of methanol are important parameters to describe the thermodynamic behavior of the system. Briefly, a risein temperature increases the molar concentration of methanol in the vapor phase, reducing its molar concentration in the liquid phase where the reaction takes place (Cambon et al., 2009). Furthermore, polar solvents, such as methanol $(\log \mathrm{P}=$ -0.8 ), may affect enzyme stability since they may promote the unfolding of the protein chain (denaturation), the loss of its structural water molecules, inhibition or chemical modifications. The latter two are very dependent of the solvent type. Additionally, the reaction conversion at equilibrium can be shifted dramatically by changing, for instance, temperature and solvent (Von Stockar, 2013). In this case, there is a combination of solvent effects and higher temperature exposition, leading to a decrease in catalytic activity. 


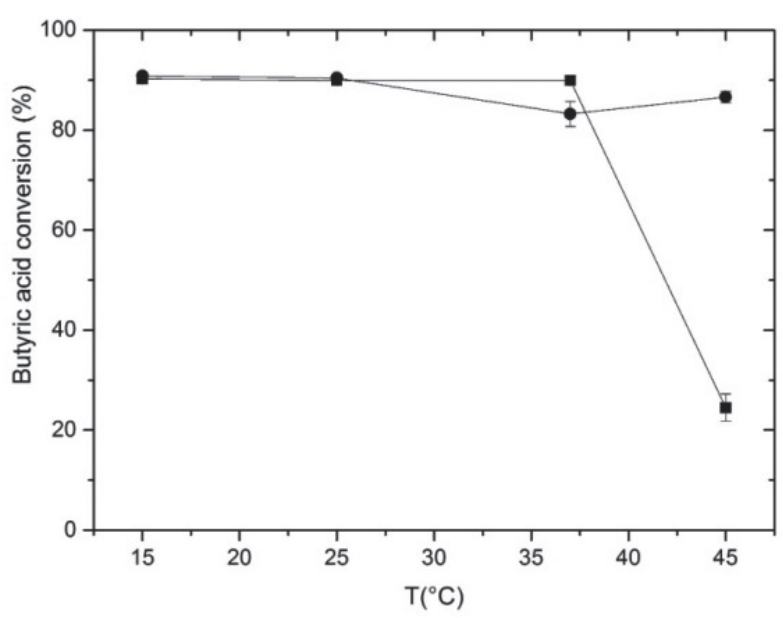

Figure 3. Effect of temperature on methyl and ethyl butyrate biosynthesis. The alcohols used were: ethanol ( $\square$ ) and methanol $(\bullet)$. Reactions were carried out using CALB-MNPs $=80$ U.., 150 $\mathrm{rpm}$, heptane, $0.2 \mathrm{~mol} / \mathrm{L}$ butyric acid, 1:1 (butyric acid: (methanol or ethanol)) and $8 \mathrm{~h}$ reaction time. Reaction volume $=1.0 \mathrm{~mL}$. Derivative mass $=0.01 \mathrm{~g}$.

The same authors (Cambon et al., 2009), investigating the synthesis of alkyl esters from vegetable oils, observed a reduction of $15 \%$ in the alkyl esters conversion within the temperature range of 30 up to $55^{\circ} \mathrm{C}$, achieving a maximum conversion rate at $30^{\circ} \mathrm{C}$. These results are in accordance with those obtained in this work, in which the conversion decreased with increasing temperature, with a maximum conversion rate at $25^{\circ} \mathrm{C}$.

Other authors studied the effect of the temperature in ethyl butyrate production catalyzed by Novozym ${ }^{\circledR}$ 435 (Rodriguez-Nogales et al., 2005). The maximum conversion rate was $75 \%$ at $35{ }^{\circ} \mathrm{C}$, showing a substantial reduction as temperature increased from 20 up to 80 ${ }^{\circ} \mathrm{C}$. The results presented in our work were better than those obtained by Rodriguez et al.(Rodriguez-Nogales et al.,2005), since a conversion rate of $90 \%$ was observed for ethyl butyrate at $25^{\circ} \mathrm{C}$.

\section{Effect of substrate concentrations}

The influence of substrate concentration was investigated using CALB-MNP and the results are shown in Figure 4. For ethyl butyrate, a conversion greater than $97 \%$ was achieved after $8 \mathrm{~h}$ at $0.4 \mathrm{~mol} / \mathrm{L}$ of substrate (1:1, molar ratio), decreasing to $86.5 \%$ at $1.0 \mathrm{~mol} / \mathrm{L}$. For methyl butyrate synthesis, the conversion was greater than $93 \%$ after $8 \mathrm{~h}$ at $0.5 \mathrm{~mol} / \mathrm{L}$ of substrate $(1: 1$, molar ratio), decreasing to $87.9 \%$ at $1.0 \mathrm{~mol} / \mathrm{L}$. These results are in agreement with the literature (Guillén et al., 2012), where ethyl butyrate was produced by lipase immobilized on polymeric resin, with a yield above $99 \%$, but at $24 \mathrm{~h}$ reaction.

Increasing the methanol concentration in the reaction medium initially provided an enhancement in the conversion

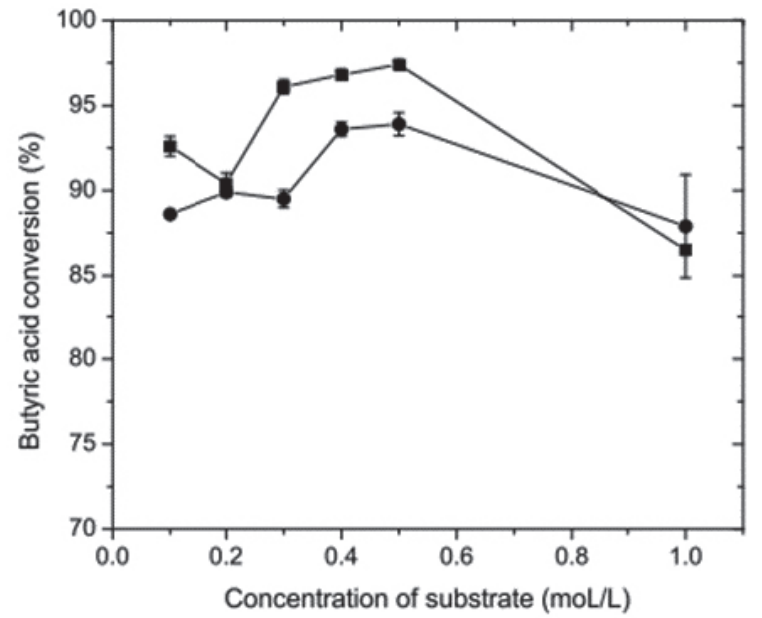

Figure 4. Effect of concentration of substrates on methyl and ethyl butyrate biosynthesis. The alcohols used were: ethanol (ם) and methanol $(\bullet)$. Reactions were carried out using CALB-MNPs $=80$ U., $25^{\circ} \mathrm{C}, 150 \mathrm{rpm}$, heptane, 0.1-1.0 mol/L butyric acid, 1:1 (butyric acid: (methanol or ethanol)) and $8 \mathrm{~h}$ reaction time. Reaction volume $=1.0 \mathrm{~mL}$. Derivative mass $=0.01 \mathrm{~g}$.

rate of butyric acid into methyl butyrate. However, the conversion values for methyl butyrate were lower than those obtained for ethyl butyrate. As previously discussed, this behavior can be related to the higher evaporation of methanol from the media compared to ethanol, since the former is more volatile than the latter.

Other authors (Abbas et al., 2003; Gandhi et al., 2008; Sun et al., 2009) reported that the methanol molecules are able to bind to the to the active sites of the enzyme, limiting the amount of energy released and consequently preventing the enzyme from changing its conformation to the desired catalytic form. In other words, the enzyme might be partially inhibited in the presence of methanol (Sun et al., 2009).Alcohols have the property of binding to proteins and induce their dehydration, resulting in a drastic loss of enzymatic activity. Thus, in our work, the greatest inhibition effects occurred at the highest concentration values, and correlated with the alcohol solubilization in the reaction medium.

The approach of using equal concentrations of alcohol and acid was also studied by Dave and Madamwar (Dave et al., 2005; Dias et al., 1991). Similar results were reported for Candida rugosa lipase immobilized on silicagel, using hexane as solvent and butyric acid - ethanol as reagents (1:1 molar ratio), obtaining conversions of $95 \%$ and $70 \%$ for reactant concentrations of 0.2 and $0.3 \mathrm{~mol} / \mathrm{L}$, respectively. In our work, the best condition was reached at a concentration of $0.4 \mathrm{~mol} / \mathrm{L}$, resulting in a conversion of $97 \%$.

\section{Effect of acid to alcohol molar ratio}

The effect of the alcohol/acid ratio on the esterification conversion was investigated by first maintaining the 
concentration of acid constant and varying the concentration alcohol, and then maintaining the concentration alcohol constant and varying the concentration of acid. Figure 5shows that a maximum conversion was obtained with 1:1 molar ratio (acid to ethanol). The excess of alcohol did not affect drastically the methyl and ethyl butyrate synthesis. Similar results for ester synthesis using CALB were described in the literature (Watanabe et al., 2002; Nordblad et al., 2008; Huang et al., 2010; Xie et al., 2012).

When in excess, the acid led to a decrease in the conversion rate from $93.4 \%$ to $7.4 \%$ for methyl butyrate and $96.8 \%$ to $24.7 \%$ for ethyl butyrate. According to several authors (Claon et al., 1994, Nordblad et al., 2008, Romero et al., 2005, Jin et al., 2012), this rapid drop in conversion rate with increasing excess of butyric acid implies that the substrate was inhibited by this substance. Literature studies suggest that acid and alcohol inhibit lipases through similar mechanisms of competitive inhibition (Nordblad et al., 2008), meaning that a second acid molecule could interfere with the deacylation of the enzyme by blocking the access to the active site (Hari et al., 2001). Moreover, the increase in acid concentration increases the proton content in the system, which could then reduce the enzymatic activity by detrimental protonation (Nordblad et al., 2008). The greatest reaction efficiency was achieved at a butyric acid concentration of 0.4 and $0.5 \mathrm{~mol} / \mathrm{L}$ ( $1: 1$ molar ratio) for the esterification to methyl and ethyl butyrate, respectively.

\section{Effect of stirring speed}

Since the stirring speed is an essential parameter due to its substantial effect on the mass transfer, its effect for the methyl and ethyl butyrate synthesis was evaluated, as shown in Figure 6. According to the profile obtained in this study, stirring speeds between 50 and $200 \mathrm{rpm}$ promote conversion rates of $80 \%$ to above $90 \%$ for both esters. Other authors (Mahapatra et al., 2009) investigated the influence of stirring speed on mass transfer and concluded that an increase in the stirring speed decreased the film thickness around the solid particles, reducing the mass transfer resistance. As presented in Figure 6, the best results were at $150 \mathrm{rpm}$ for both produced esters.

The minor effect of stirring speeds between 50 e 200 rpm on mass transfer can be explained by the fact that nanoparticles present a large surface area, resulting in a greater dispersion of the enzyme, which thus prevents its aggregation and enhances the mass transfer in the system (Nagayama et al., 2002, Dandavate et al., 2009). The sharp drop of methyl butyrate conversion rate at the speed of $250 \mathrm{rpm}$ suggests that the methanol molecules are more likely to pass to the vapor phase under this condition, as previously discussed.

\section{Production of flavor esters in the presence of organic solvents}

The hydrophobic behavior is important in stabilizing the

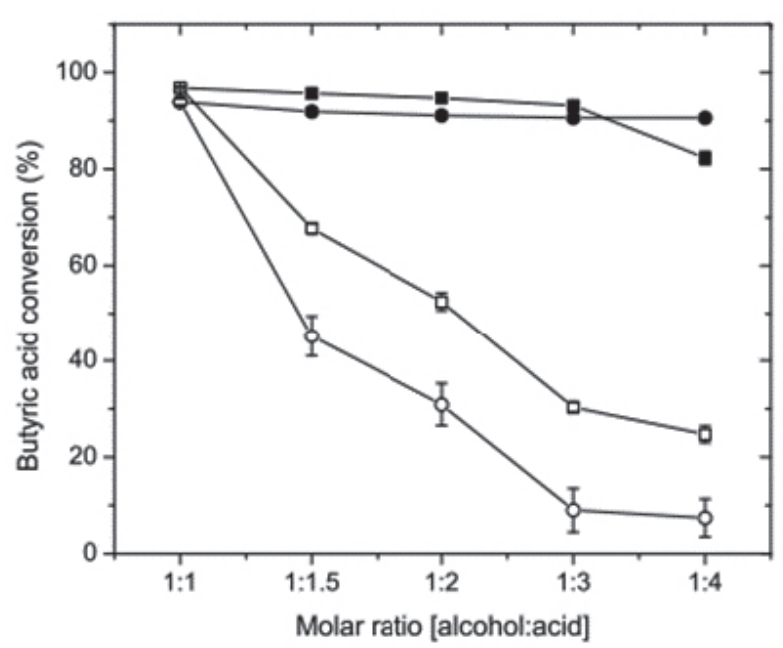

Figure 5. Effect of molar ratio on methyl and ethyl butyrate biosynthesis. Varying the concentration of alcohol ( $\square)$ and acid (口) to ethyl butyrate. Varying the concentration of alcohol (•) and acid (o) to methyl butyrate. Reactions were carried out using CALB-MNPs = $80 \mathrm{U} ., 25^{\circ} \mathrm{C}, 150 \mathrm{rpm}$, heptane, $0.5 \mathrm{~mol} / \mathrm{L}$ (methanol) and $0.4 \mathrm{~mol} / \mathrm{L}$ (ethanol), 1:1-1:4 (butyric acid: (methanol and ethanol)) and $8 \mathrm{~h}$ reaction time. Reaction volume $=1.0 \mathrm{~mL}$. Derivative mass $=0.01 \mathrm{~g}$

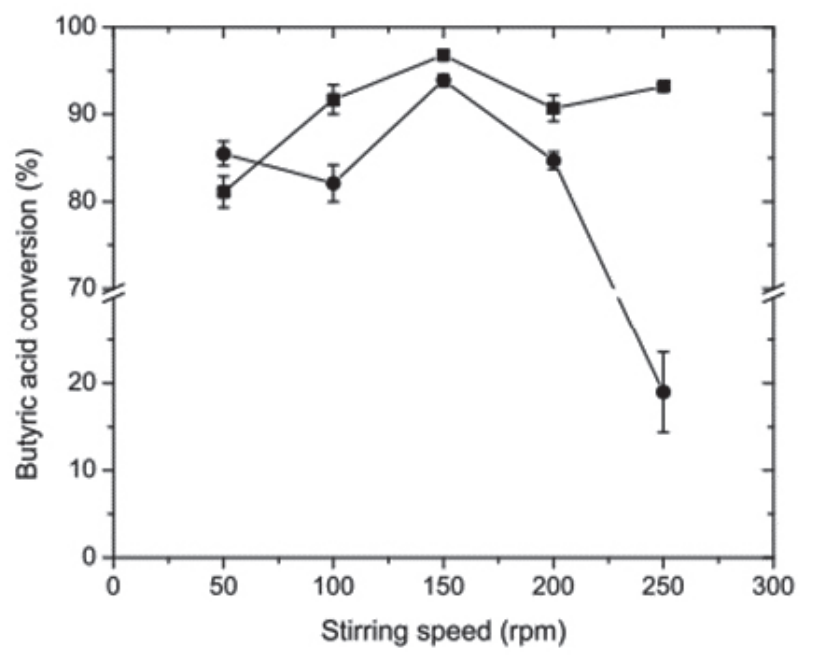

Figure 6. Effect of shaking speed on methyl and ethyl butyrate biosynthesis. The alcohols used were: ethanol ( $\bullet$ ) or methanol $(\bullet)$. Reactions were carried out using CALB-MNPs $=80$ U., $25^{\circ} \mathrm{C}, 150$ $250 \mathrm{rpm}$, heptane, 0.5 (methanol) and 0.4 (ethanol) mol/L butyric acid, 1:1 (butyric acid: (methanol and ethanol)) and $8 \mathrm{~h}$ reaction time. Reaction volume $=1.0 \mathrm{~mL}$. Derivative mass $=0.01-0.50 \mathrm{~g}$.

catalysts in a non-aqueous environment (Sun et al., 2009). The parameter $\log P$, the partition coefficient of the solvent between 1-octanol and water, is a quantitative measure of the solvent polarity often used to predict possible effects on the catalytic activity of the enzyme in organic environments (Laane et al., 1987). Therefore, the production of methyl and ethyl butyrate by CALB-MNP was also studied in the presence of different organic solvents (in order of increasing hydrophobicity): 1,4-dioxane, cyclohexane, hexane and heptane. Table 1 shows the relationship 
between $\log P$ and the conversion rate of esters. Increasing the organic solvent hydrophobicity (greater $\log P$ ) leads to a significant increment of conversion rate for both studied butyrates, confirming its dependence on the type of solvent. The maximum substrate conversion was obtained in the presence of heptane: $96.8 \%$ for ethyl butyrate and $93.9 \%$ for methyl butyrate. Studies have shown that the reaction outcome is better with non-polar solvents, due to the fact that polar solvents could distort the water layer around lipase (Ben Salah et al., 2007. A small amount of water around the enzyme molecules is essential to maintain the enzyme activity (Laane et al., 1987). The results of this study are consistent with those described in the literature, in which solvents with $\log P>2$ support higher levels of enzyme activity (Guillén et al., 2012, Xu et al., 2002, Sun et al., 2009, Nordblad et al.,2008).Another important aspect of the solvents is the dielectric constant. Electrostatic forces are a crucial factor in enzymatic catalysis as they are responsible forstabilizing the transition state of the enzyme (Warshel et al., 1989, Park et al., 2001).

Table 1. Effect of organic solvents on methyl and ethyl butyrate biosynthesis. Reactions were carried out using CALB-MNPs $=80 \mathrm{U}$., $25^{\circ} \mathrm{C}$, $150 \mathrm{rpm}, 0.5$ (methanol) and 0.4 (ethanol) mol/L butyric acid, 1:1 (butyric acid: (methanol or ethanol)) and $8 \mathrm{~h}$ reaction time. Reaction volume $=1.0 \mathrm{~mL}$. Derivative mass $=0.01 \mathrm{~g}$.

\begin{tabular}{lcccc}
\hline Solvent & Dielectric constant & $\log P$ & Butyric acid conversion & Methyl \\
\hline Heptane & & & Ethyl & $93.9 \pm 0.67$ \\
Hexane & 1.92 & 4.0 & $96.8 \pm 0.3$ & $84.3 \pm 1.3$ \\
Cyclohexane & 1.88 & 3.5 & $83.7 \pm 1.4$ & $78.4 \pm 2.5$ \\
1,4-Dioxane & 2.02 & 3.2 & $84.7 \pm 2.4$ & $49 \pm 2.8$ \\
\hline
\end{tabular}

It is expected that solvents with low dielectric constant will further stabilize the enzyme tetrahedral transition state compared to those with high dielectric constant, providing a higher conversion rate (Warshel et al., 1989).This behavior was observed for 1,4-dioxane and cyclohexane, in which the lower dielectric constant yielded an increase of $50 \%$ in the conversion rate, as shown in Table 1. However, the results for hexane were unexpected. Although it should provide a greater conversion according to the stability analysis, the best results were obtained for heptane.

The ethanol esterification with butyric acid in the presence of hexane and heptane is reported by several authors (Dias et al., 1991; Manjon et al.,1991; Dave et al., 2005; Rodriguez-Nogales et al., 2005; Aragão et al., 2011). The best results were obtained by Manjon et al. (1991) using $R$. miehei lipase immobilized in Celite as catalyst and hexane as solvent. The results in Table 1 are consistent with the literature.

\section{Reaction Time Dependence}

The conversion time profile is shown in Figure 7. For the same time period of one hour, the conversion of substrates differed depending on the nature of the alcohols. The highest conversions were obtained for both ethyl (96.8 \%) and methyl butyrate $(93.9 \%)$ under an incubation time of $8 \mathrm{~h}$. Then, no further increase in conversion was observed, even for longer periods. A similar behavior was found by other authors (Abbas et al., 2003), who obtained distinct reaction rates for the three different alcohols during the first 2 hours of experiment, suggesting that the reaction rate is dependent on the nature of the alcohol.

The literature (Dias et al., 1991; Manjon et al., 1991; Dave et al., 2005, Rodriguez-Nogales et al., 2005; Aragão

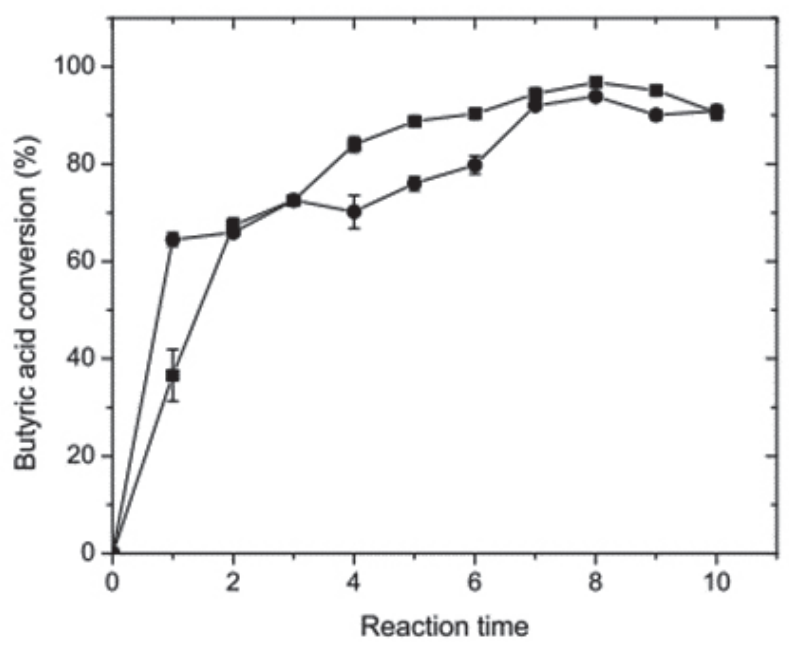

Figure 7. Kinetics of ethyl and methyl butyrate biosynthesis. The alcohols used were: ethanol $(\boldsymbol{\square})$ and methanol $(\bullet)$. Reactions were carried out using CALB-MNPs $=80 \mathrm{U}$., at $25^{\circ} \mathrm{C}, 8 \mathrm{~h}, 150 \mathrm{rpm}$, heptane, 0.5 (methanol) and 0.4 (ethanol) $\mathrm{mol} / \mathrm{L}$ butyric acid, $1: 1$ (butyric acid: (methanol or ethanol)) . Reaction volume $=1.0 \mathrm{~mL}$. Derivative mass $=0.01 \mathrm{~g}$.

et al., 2011, Grosso et al., 2012) reports the effect of several different immobilized lipases in the production of ethyl butyrate. For instance (Rodriguez-Nogales et al.,2005), the reaction with butyric acid and ethanol catalyzed by CALBacrylic resin (Novozym 435, Novozymes, Denmark) in 10 $\mathrm{mL}$ of n-heptane, with a concentration of acid and alcohol of $0.04 \mathrm{~mol} / \mathrm{L}$ and $0.52 \mathrm{~mol} / \mathrm{L}$, respectively, was carried out and $75 \%$ of conversion was achieved in 96 hours. Another paper (Aragão et al., 2011) reports a conversion of $88 \%$ into ethyl butyrate, in $3 \mathrm{~h}$ of reaction, $40 \mathrm{~mL}$ of reactional volume, using lipase from Mucor miehei, immobilized on commercial resin beads. 
The best volumetric production of $26.4 \mu \mathrm{mol} /(\mathrm{mL} . \mathrm{h})$ of ethyl butyrate presented in the literature(Dias et al., 1991; Manjon et al., 1991, Grosso et al., 2012, Pires-Cabral et al., 2010; Dave et al., 2005; Rodriguez-Nogales et al., 2005; Aragão et al., 2011) was presented by Aragão et al. (2011) using a lipase from Mucor miehei immobilized in commercial resin beads. The result obtained in our work, using CALB-MNP, was $53.7 \mathrm{~mol} /(\mathrm{mL} . \mathrm{h})$, twice the value presented by Aragão et al. (2011).

\section{Operational Stability}

The operational stability of the immobilized system was investigated in the synthesis of methyl and ethyl butyrate, and the results are shown in Figure 8 and 9, respectively. Consecutive reaction cycles were performed using $0.01 \mathrm{~g}$ of CALB-MNPfor $8 \mathrm{~h}$ at $25^{\circ} \mathrm{C}, 150 \mathrm{rpm}, 0.4$ and $0.5 \mathrm{~mol} / \mathrm{L}$ butyric acid, 1:1 (butyric acid: (methanol or ethanol)). Reaction volume $=1.0 \mathrm{~mL}$ (heptane). The same conditions were used with Novozym ${ }^{\circledR} 435$ (= 80 U.).

As shown in Figure 8, in the synthesis of methyl butyrate, a conversion rate of $89.6 \%$ was achieved with Novozym ${ }^{\circledR} 435$ in the first cycle. According to Figure 9,

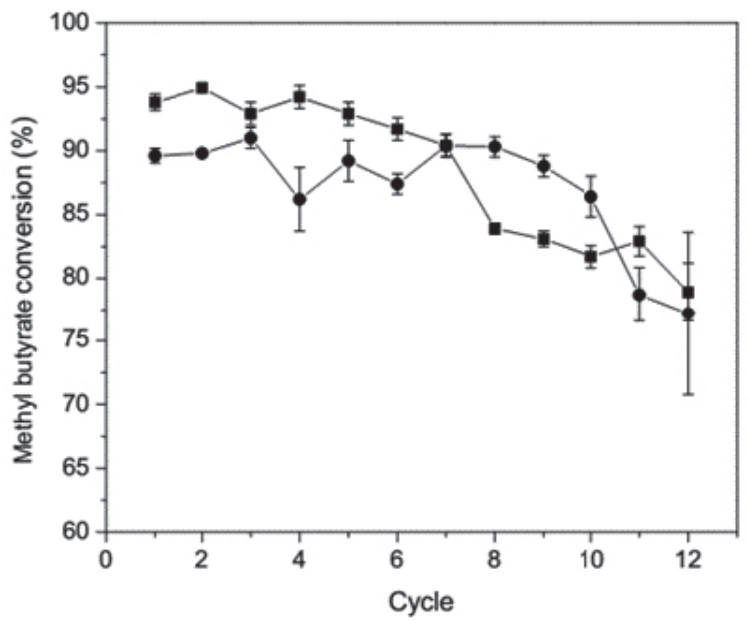

Figure 8. Operational stability of CALB-MNPs (-) and CALBacrylic resin $(\bullet)$ in the methyl butyrate biosynthesis. Reactions were carried out at $25^{\circ} \mathrm{C}, 8 \mathrm{~h}, 150 \mathrm{rpm}, 0.4 \mathrm{~mol} / \mathrm{L}$ butyric acid, $1: 1$ (butyric acid: methanol). Reaction volume $=1.0 \mathrm{~mL}$. Derivative mass $=0.01 \mathrm{~g}$

of 8 hours each, showing the potential use of CALB-MNP in reactions of industrial interest.

\section{CONCLUSIONS}

The study showed that magnetic nanoparticles modified by APTS and glutaraldehyde are a material capable of both supporting the active enzyme CALB and preserving its for ethyl butyrate, the conversion using Novozym ${ }^{\circledR}$ 435 was $95.6 \%$ at the first cycle; however, the highest conversions were accomplished employing CALB-MNP for both methyl and ethyl butyrate, obtaining a 93.9 and $95.6 \%$ conversion, respectively.

For both biocatalysts, the immobilized enzyme was quite stable for up to 10 cycles of esterification, since it retained more than $80 \%$ of its initial esterification activity, see Figure 8 and 9. At the end of the last cycle (12), for ethyl butyrate synthesis, CALB-MNP maintained more than $74 \%$ of its catalytic activity and Novozym ${ }^{\circledR} 435$, $81 \%$, see Figure 9.

Comparing the results with the literature (Guillén et al., 2012; Pires-Cabral et al., 2010; Manjon et al., 1991; Rodriguez-Nogales et al., 2005), the greatest bioconversion for ethanol esterification with butyric acid catalyzed by immobilized lipases was obtained by Guillen et al. (2012) using immobilized Rhizopus oryzae lipase on octadecyl sepabeads, achieving $99.1 \%$ in 24 hours. Despite the high value, this conversion was unable to withstand more than 3 consecutive cycles, presenting a substantial decrease of $40 \%$ after six cycles. In the present study, the catalytic activity was maintained at $93.4 \%$ for 9 consecutive cycles

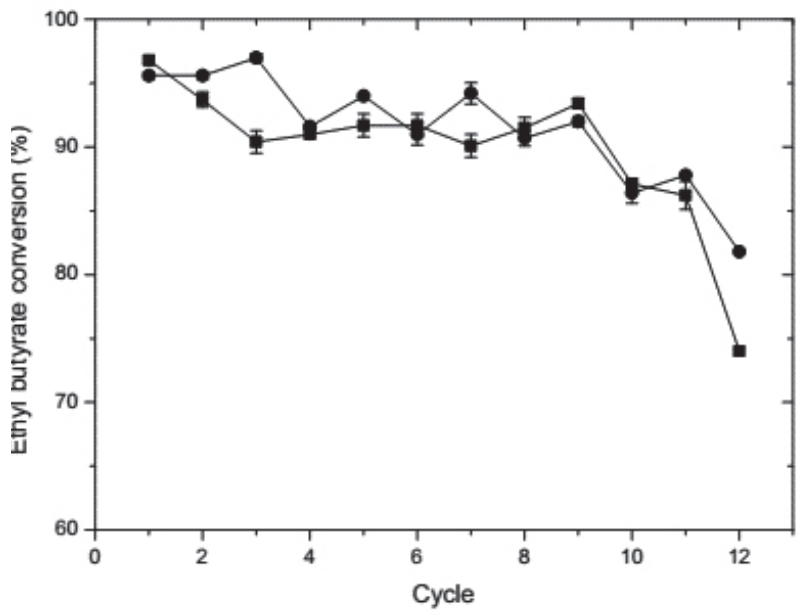

Figure 9. Operational stability of CALB-MNPs $(\bullet)$, acrylic resin (•) in the ethyl butyrate biosynthesis. Reactions were carried out at 25 ${ }^{\circ} \mathrm{C}, 8 \mathrm{~h}, 150 \mathrm{rpm}, 0.4 \mathrm{~mol} / \mathrm{L}$ butyric acid, $1: 1$ (butyric acid: ethanol). Reaction volume $=1.0 \mathrm{~mL}$. Derivative mass $=0.01 \mathrm{~g}$.

catalytic activity even after consecutive reaction cycles. Analyzing the results of the different effects on the ester bioconversion, there is a strong influence of alcohol, acid and molar ratio of substrates. The experiments could not be performed under higher temperatures due to the high volatility of methanol. Increasing the molar ratio of acid might lead to the denaturation of the enzyme, compromising the ester synthesis. The effect of hydrophobicity of the solvent was very pronounced, non-polar solvents are 
more suitable for esterification reactions catalyzed by CALB-MNP. The biocatalyst studied in this work, CALBMNP, promoted efficient biosynthesis of methyl and ethyl butyrate. The optimal conditions for synthesizing methyl and ethyl butyrate by CALB-MNP resulted in a substrate conversion of $96.8 \%$. The CALB-MNP biocatalyst was able to preserve most of its catalytic activity even after 12 consecutive reaction cycles. These results are satisfactory when compared with the commercial immobilized enzyme. Thus, the use of CALB-MNP is particularly advantageous in ester production.

\section{ACKNOWLEDGMENTS}

The authors would like to thank the Brazilian researchfunding agencies, CNPq and CAPES.

\section{REFERENCES}

Abbas, H., and Comeau, L., Aroma synthesis by immobilized lipase from Mucor sp., Enzyme and Microbial Technology, 32, no. 5, 589-595 (2003).

Ansari, S.A., Husain, Q., Potential applications of enzymes immobilized on/in nano materials: A review, Biotechnol Adv., 30, no. 3, 512-23 (2012).

Aragão, V. C., Porto, M.R.A., Burkert, C.A.V., Kalil, S.J. and Burkert, J.F.M., Response surface methodology approach for the synthesis of ethyl butyrate, Food Technol. Biotechnol. 49 (1) 103-110 (2011).

AOCS. Official Methods and Recommended Practices of the American Oil Chemist's Society, 6th ed. (2013).

Barreto, A. C. H., Maia, F. J. N., Santiago, V. R., Ribeiro, V. G. P., Denardin, J. C., Mele, G., Carbone, L., Lomonaco, D., Mazzetto, S. E. and Fechin, P. B. A., Novel ferrofluids coated with a renewable material obtained from cashew nut shell liquid, Microfluidics and Nanofluidics, 12(5), 677-686 (2012).

Ben Salah, R., Ghamghui, H., Miled, N., Mejdoub, H. and Gargouri, Y., Production of butyl acetate ester by lipase from novel strain of Rhizopus oryzae, Journal of Bioscience and Bioengineering, 103, no. 4, 368-372 (2007).

Bjorkling, F., Godtfredsen, S.E. and Kirk, O., The future impact of industrial lipases, Trends in Biotechnology, 9, no. 1, 360363 (1991).

Bleicher, L., Sasaki, J.M. and Santos, C.O.P., Development of a graphical interface for the Rietveld refinement program DBWS. Journal of Applied Crystallography, 33, 1189-1190 (2000).

Boyer, C., Whittaker, M. R., Bulmus, V., Liu, J., and Davis, T. P., The design and utility of polymer-stabilized iron-oxide nanoparticles for nanomedicine applications. NPG Asia Materials, 2, no. 1, 23-30 (2010).

Bradford, M. M., A rapid and sensitive method for the quantitation of microgram quantities of protein utilizing the principle of protein-dye binding, Anal Biochem, 72, no. 7, 248-254 (1976).
Cambon, E., Bourlieu, C., Salum, T. F. C., Piombo, G., Dubreucq, E. and Villeneuve, P., Ability of Vasconcellea $x$ heilbornii lipase to catalyse the synthesis of alkyl esters from vegetable oils, Process Biochemistry, 44, no. 11, 1265-1269 (2009).

Claon, P. A., and Akoh, C. C., Effect of reaction parameters on SP435 lipase-catalyzed synthesis of citronellyl acetate in organic solvent Enzyme and Microbial Technology, 16, no. 10, 835-838 (1994).

Dandavate, V., Keharia, H. and Madamwar, D., Ethyl isovalerate synthesis using Candida rugosa lipase immobilized on silica nanoparticles prepared in nonionic reverse micelles, Process Biochemistry, 44, no. 3, 349-352 (2009).

Dave, R., and Madamwar, D., Esterification in organic solvents by silica gel immobilized Candida rugosa lipase, Larroche, C., Pandey, A., Dussap, C.G. (Eds.), Current Topics on Bioprocesses in Food Industry (Asiatech Press), 71-80 (2005).

Deng, X., Fang, Z., Liu, Y. and Yu., C. L. Production of biodiesel from Jatropha oil catalyzed by nanosized solid basic catalyst, Energy, 36, no. 2, 777-784 (2011).

Dias, S. F., Vilas-Boas, L., Cabral, J. M. S., and Fonseca, M. M. R., Production of ethyl butyrate by Candida rugosa lipase immobilized in polyurethane, Biocatalysis and Biotransformation, 5, no. 1, 21-34 (1991).

Dominguez de María, P., Carboni-Oerlemans, C., Tuin, B., Bargeman, G., and van Gemert, R., Biotechnological applications of Candida antarctica lipase A: State-of-the-art, Journal of Molecular Catalysis B: Enzymatic, 37, nº. 1, 36-46 (2005).

Foresti, M. L., Valle, G., Bonetto, R., Ferreira, M. L., Briand, L. E., FTIR, SEM and fractal dimension characterization of lipase B from Candida antarctica immobilized onto titania at selected conditions, Applied Surface Science, 256(6), 16241635 (2010).

Gandhi, N. N., Sawant, S. B. and Joshi, J. B., Specificity of a lipase in ester synthesis: effect of alcohol, Biotechnology Progress, 11, no. 3, 282-287 (2008).

García-Galán, M. J., Rodríguez-Rodríguez, C. E., Vicent, T., Caminal, G., Díaz-Cruz, S. M., Barceló, D., Biodegradation of sulfamethazine by Trametes versicolor: Removal from sewage sludge and identification of intermediate products by UPLC-QqTOF-MS. Science of The Total Environment, 409, $\mathrm{n}^{\mathrm{o}}$. 24, 5505-5512 (2011)

Gillies, B., Yamazaki, H. and Armstrong, D. W., Production of flavor esters by immobilized lipase, Biotechnology Letters, 9, $n^{\circ} .10,709-714$ (1987).

Gomes, F. M., Pereira, E. B. and de Castro, H. F., Immobilization of lipase on chitin and its use in nonconventional biocatalysis, Biomacromolecules, 5, no. 1, 17-23 (2004).

Grosso, C, Ferreira-Dias, S. and Pires-Cabral, P., Modelling and optimization of ethyl butyrate production catalysed by Rhizopus oryzae lipase, Journal of Food Engineering (2012).

Guillén, M., Benaiges, M. D. and Valero, F., Biosynthesis of ethyl butyrate by immobilized recombinant Rhizopus oryzae lipase expressed in Pichia pastoris, Biochemical Engineering Journal (2012).

Hari Krishna, S., and Karanth, N. G., Lipase-catalyzed synthesis of isoamyl butyrate: a kinetic study, Biochimica et Biophysica 
Acta (BBA)-Protein Structure and Molecular Enzymology, 1547, no. 2, 262-267 (2001).

Hasan, F., Shah, A. A. and Hameed, A., Industrial applications of microbial lipases, Enzyme and Microbial Technology, 39, no. 2, 235-251 (2006).

Huang, Y., Zheng, H., and Yan, Y., Optimization of lipasecatalyzed transesterification of lard for biodiesel production using response surface methodology, Appl. Biochem. Biotechnol. 60, 504-515 (2010).

Hung, T. C., Giridhar, R., Chiou, S. H. and Wu., W. T., Binary immobilization of Candida rugosa lipase on chitosan, Journal of Molecular Catalysis B: Enzymatic 26, no. 1, 69-78 (2003).

Idris, A., and Bukhari, A., Immobilized Candida antarctica lipase B: Hydration, stripping off and application in ring opening polyester synthesis, Biotechnology advances (2011).

Jin, Z., Ntwali, J., Han, S. Y., Zheng, S. P. and Lin., Y., Production of flavor esters catalyzed by CALB-displaying Pichia pastoris whole-cells in a batch reactor, Journal of Biotechnology (2012).

Laane, C., Boeren, S., Vos, K. and Veeger, C., Rules for optimization of biocatalysis in organic solvents, Biotechnology and Bioengineering, 30, no. 1, 81-87 (1987).

Mahapatra, P., Kumari, A., Kumar Garlapati, V., Banerjee, R. and Nag, A., Enzymatic synthesis of fruit flavor esters by immobilized lipase from Rhizopus oligosporus optimized with response surface methodology, Journal of Molecular Catalysis B: Enzymatic, 60, no. 1, 57-63 (2009).

Manjon, A., Iborra, J. L. and Arocas, A., Short-chain flavour ester synthesis by immobilized lipase in organic media, Biotechnology Letters, 13, no. 5, 339-344 (1991).

McCabe, R. W., Rodger, A., and Taylor, A., A study of the secondary structure of Candida antarctica lipase B using synchrotron radiation circular dichroism measurements, Enzyme and Microbial Technology, 36, no.1, 70-74 (2005).

Nagayama, K., Yamasaki, N. and Imai, M., Fatty acid esterification catalyzed by Candida rugosa lipase in lecithin microemulsion-based organogels, Biochemical Engineering Journal, 12, no. 3, 231-236 (2002).

Netto, C. G. C. M., Andrade, L. H. and Toma. H. E., Enantioselective transesterification catalysis by Candida antarctica lipase immobilized on superparamagnetic nanoparticles, Tetrahedron: Asymmetry, 20, no. 19, 22992304 (2009).

Nordblad, M., and Adlercreutz, P., Effects of acid concentration and solvent choice on enzymatic acrylation by Candida antarctica lipase B, Journal of Biotechnology, 133, no. 1, 127-133 (2008).

Park, H., and Chi, Y. M., The enhancement of electrostriction caused by lowering the solvent dielectric constant leads to the decrease of activation energy in trypsin catalysis, Biochimica et Biophysica Acta, 1568, no. 1, 53-59 (2001).

Pires-Cabral, P., da Fonseca, M. M. R. and Ferreira-Dias, S., Esterification activity and operational stability of Candida rugosa lipase immobilized in polyurethane foams in the production of ethyl butyrate, Biochemical Engineering Journal, 48, no. 2, 246-252 (2010).
Rodrigues, D.S., Mendes, A.A., Adriano, W.S., Gonçalves, L.R.B. and Giordano, R.L.C., Multipoint covalent immobilization of microbial lipase on chitosan and agarose activated by different methods, Journal of Molecular Catalysis B: Enzymatic, 51, no. 3, 100-109 (2008).

Rodriguez-Nogales, J. M., Roura, E. and Contreras, E., Biosynthesis of ethyl butyrate using immobilized lipase: a statistical approach, Process Biochemistry, 40, no. 1, 63-68 (2005).

Romero, M. D., Calvo, L., Alba, C., Habulin, M., Primozic, M. and Knez, Z., Enzymatic synthesis of isoamyl acetate with immobilized Candida antarctica lipase in supercritical carbon dioxide, The Journal of Supercritical Fluids 33, no. 1, 77-84 (2005).

Silva, J. A., Macedo, G. P., Rodrigues, D. S., Giordano, R. L. C. and Gonçalves, L. R. B., Immobilization of Candida antarctica lipase B by covalent attachment on chitosanbased hydrogels using different support activation strategies. Biochemical Engineering Journal, 60, 16-24 (2012).

Sun, S.Y., Xu, Y. and Wang, D., Novel minor lipase from Rhizopus chinensis during solid-state fermentation: Biochemical characterization and its esterification potential for ester synthesis. Bioresource Technology, 100, no. 9, 2607-2612 (2009).

Tartaj, P., del Puerto Morales, M., Veintemillas-Verdaguer, S., Gonzàlez-Carreno, T. and Serna, C. J., The preparation of magnetic nanoparticles for applications in biomedicine. Journal of Physics D: Applied Physics, 36, no. 13, R182 (2003).

Uppenberg, J., Hansen, M. T., Patkar, S. and Jones, T. A., The sequence, crystal structure determination and refinement of two crystal forms of lipase B from Candida antarctica. Structure (Elsevier) 2, no. 4, 293-308 (1994).

Vaghari, H., Jafarizadeh-Malmiri, H., Mohammadlou, M., Berenjian, A., Anarjan, N., Jafari, N. and Nasiri, S. Application of magnetic nanoparticles in smart enzyme immobilization, Biotechnol. Lett. 10.1007/s10529-015-1977-z (2015).

Von Stockar, U., Biothermodynamics: The Role of Thermodynamics in Biochemical Engineering, EPFL Press, Switzerland (2013).

Warshel, A., Naray-Szabo, G., Sussman, F. and Hwang, J. K., How do serine proteases really work? Biochemistry, 28, no. 9, 3629-3637 (1989).

Watanabe, Y., Shimada, Y., Sugihara, A., Tominaga, Y., Conversion of degummed soybean oil to biodiesel fuel with immobilized Candida Antarctica lipase, J. Mol. Catal. B Enzym. 17, 151-155 (2002).

Xie, W., Wang, I., Immobilized lipase on magnetic chitosan microspheres for transesterification of soybean oil, Biomass and Bioenergy, 36, 373-380 (2012).

Xu, Y., Wang, D., Mu, X. Q., Zhao, G. A. and Zhang, K. C., Biosynthesis of ethyl esters of short-chain fatty acids using whole-cell lipase from Rhizopus chinesis CCTCC M201021 in non-aqueous phase. Journal of Molecular Catalysis B: Enzymatic 18, no. 1, 29-37 (2002).

Zheng G., Shu B., Yan D., Preparation and characterization of immobilized lipase on magnetic hydrophobic microspheres. Enzyme Microb Technol.,32, no. 7, 776-782 (2003). 